\title{
Cellular and clinicopathological features of the IL-33/ST2 axis in human esophageal squamous cell carcinomas
}

\author{
Guanglin Cui ${ }^{1,2^{*}} \mathbb{0}$, Jingli Ren ${ }^{3}$, Gang $X u^{1}$, Zhenfeng $\mathrm{Li}^{1}$, Wei Zheng ${ }^{1}$ and Aping Yuan ${ }^{1,4}$
}

\begin{abstract}
Background: Emerging evidence has suggested that interleukin (IL)-33 and its primary functional receptor ST2 are involved in the pathogenesis of tumorigenesis.

Methods: Using immunohistochemistry $(\mathrm{IHC})$ and double immunofluorescence staining, we characterized the cellular and clinicopathological features of the IL-33/ST2 axis in different compartments in human esophageal squamous cell carcinoma (ESCC) surgical specimens.

Results: IHC data revealed an increased expression of IL-33-immunoreactivity (IR) and ST2-IR located in both ESCC cells and tumor stromal cells; which were associated with advanced clinicopathological features such as TNM stages and node involvement. However, the Kaplan-Meier analysis showed that densities of neither IL-33 positive nor ST2 positive cells in both the ESCC mass and stroma were associated with the overall survival rate in patients with ESCC. Double immunofluorescence staining for cellular feature analysis demonstrated that these IL-33 positive and ST2 positive cells in ESCCs were with a high proliferation rate, and IL-33-IR was frequently co-expressed with ST2-IR in both ESCC and stromal cells.

Conclusion: Significant altered cellular features of the IL-33/ST2 axis in ESCCS were associated with advanced clinicopathological variables. The data suggest that the IL-33/ST2 axis might be involved in the progression of human ESCCs.
\end{abstract}

Keywords: Esophagus, Carcinoma, Interleukin-33, Progression

\section{Background}

Esophageal cancer remains a highly lethal malignancy in which a frequency that varies greatly across different geographic locations [1]. Esophageal cancers are histologically subdivided into two main histologic types: adenocarcinoma and esophageal squamous cell carcinoma (ESCC). Adenocarcinoma is more common in Western countries like United States, Western and Northern Europe, whereas ESCC is more frequent seen in regions so-called "Asian esophageal cancer belt" that encompasses areas such as Iran, Kazakhstan and northern and central China [1]. Incidence of ESCC in our location

\footnotetext{
${ }^{*}$ Correspondence: guanglin.cui@nord.no

2 Faculty of Health Science, Nord University, Campus Levanger, Levanger, Norway

Full list of author information is available at the end of the article
}

(Henan province, Central China) is high and remains difficult to cure [2], primarily because of its extremely aggressive nature and frequent regional lymph node metastasis even at initial diagnosis [2, 3]. Due to this fact, much research have recently focused on mechanisms involving in ESCC tumor invasion and progression [4-7].

The precise mechanisms for ESCC progression remain unclear, though several potential mechanisms have been hypothesized and evaluated [8]. There is abundant evidence that chronic inflammation is a driving force in the majority of human malignancies including ESCC [8, 9]. Inflammatory factors released from the tumor microenvironment may lead to tumor invasion, angiogenesis and metastasis [10], which are closely associated with the prognosis in patients with ESCC $[10,11]$. Thus, investigating the regulatory role of inflammatory network in the tumor microenvironment 
may provide not only new insights into mechanisms of ESCC progression, but also a potential therapeutic significance in the context of human cancers.

Interleukin (IL)-33 is a novel inflammatory cytokine, it plays an important role in the regulation of host immune function [12-14] and immune cell expansion [15-18], and has been associated with the development of human inflammatory diseases (IBD) [19, 20], as well as tumors [21-31]. Moreover, studies have also revealed that high expression of IL-33 is associated with disease progression and poor prognosis in diverse cancers [25, 27, 28, 32-34]. Thus, studies regarding the role of IL-33 in tumor development has attracted much attention and evidence is accumulating. Current data strongly suggest that IL-33 is involved in the pathogenesis of cancers [16, 18, 23, 31, 34-37].

Regarding mechanisms of IL-33 promoting tumorigenesis, studies have suggested that that the IL-33 may regulate the expansion and function of different $\mathrm{T}$ cell subsets $[15,16]$, ILC2s [18] and nature killer (NK) cells $[17,18]$, stimulate the process of angiogenesis [36, 38-40], inhibit antitumor immunity [21, 24, 41] and promote tumor cell growth [25]. For instance, recent progression has uncovered important roles of IL-33 in the stimulation of regulatory $\mathrm{T}$ cell (Treg) expansion and function [21, 30, 42, 43], whereas Tregs are important for the establishment and maintenance of immunosuppressive and immune tolerance in patients with cancers [44, 45]. Moreover, clinical studies have shown that increased expression of IL-33 links to the tumor invasion, metastasis [21, 25, 26, 35, 42, 46-50] and prognosis in patients with cancers [25, 34, 46]. More recently, we have demonstrated significant increased expression of IL-33 and ST2 from the colorectal precancerous (adenoma) lesion to cancerous lesion; IL-33-immunoreactivity (IR) and St2-IR are not only expressed in tumor cells, but also in surrounding stromal cells, indicating a mixt cellular source of IL-33 and ST2 in the tumor microenvironment [35]. Recently, the role of IL-33 in inducing esophageal inflammation has also been studied. Experimental evidence suggested that IL-33 contributes to the induction of chronic inflammation in esophagus and is involved in the pathogenesis of esophageal inflammatory diseases [51-53]. However, knowledge is still lacking about the role of IL-33/ST2 axis in human ESCC.
Therefore, the aim of this study was to characterize cellular features including presentation, proliferative rate, and autocrine loop of IL-33/ST2 axis presents in both ESCC and stromal cells, as well as its clinical significance.

\section{Methods}

Study population and tissue samples

A total of 41 patients with primary ESCC, who were diagnosed and treated in the Second Affiliated Hospital of Zhengzhou University between 2010 and 2013, were enrolled. Of these 41 patients, 26 were male and 15 were female. The age of mean at treatment for ESCCs was 56.33 years (age ranging from 32 to 76 years). Tumor location (upper/middle/lower) was 5/27/9. The pathological diagnosis and clinicopathological classification was reviewed by a senior pathologist JR from Department of Pathology according to the seventh edition of the pathologic tumor-node-metastasis (TNM) classification 2009 [54]. No patient received radiotherapy and/or chemotherapy preoperatively. No patients with Barrett's esophagus, $65.38 \%(17 / 26)$ males with cigarette smoking and all females without cigarette smoking. Twenty nontumor esophageal tissues taken from far distant locations $(\sim 10 \mathrm{~cm}$ from tumor mass) in patients with ESCC served as controls (age of mean 54.35 years, range 27-72 years; male/female: 13/7. Specimen location, upper/middle/ lower: 7/3/9); six male controls with cigarette smoking and 14 without, microscopic examination showed all the controls are in normal morphology. Basic clinicopathological characteristics of patients with ESSC is summarized in Table 1. This work was approved by the local Medical Research Committee of the Second Affiliated Hospital, Zhengzhou University.

\section{Immunohistochemistry (IHC)}

IHC for IL-33 and ST2 were performed with a Vectastain Elite $A B C$ Kit (Vector Lab., Burlingame, CA, USA) according to the manufacturer's instructions and our published methods $[35,55,56]$. The following primary antibodies were used: goat anti-IL-33 polyclonal antibody (working dilution 1:100; R\&D systems, Minneapolis, MN, USA) and rabbit anti-ST2 polyclonal antibody (working dilution 1:100; Thermo Scientific., Rockford, USA). Antibodies were incubated at $4{ }^{\circ} \mathrm{C}$ overnight. 3-Amino9-ethylcarbazole (AEC; Vector Laboratories, Burlingame, CA, USA) was used as chromogen, and slides were

Table 1 Basic pathological information of ESSC patients

\begin{tabular}{|c|c|c|c|c|c|c|c|c|}
\hline & \multirow[t]{2}{*}{$\mathbf{N}$} & \multicolumn{3}{|c|}{ TNM } & \multicolumn{2}{|c|}{ Invasion depth } & \multicolumn{2}{|c|}{ Lymph node } \\
\hline & & I & II & III & Muscular & All layer & + & - \\
\hline ESCC & 41 & 1 & 9 & 31 & 8 & 33 & 6 & 35 \\
\hline
\end{tabular}


slightly counterstained with Mayer's hematoxylin. Previous known colorectal adenoma/carcinoma sections shown to have IL-33 and ST2 IRs were used as positive controls to confirm the IL-33 and ST2 IRs in each series of IHCs. To exclude background staining by nonspecific antibody binding, negative controls were included using isotype-matched antibodies in each IHC test.

\section{Double immunofluorescence (DIF) for the examination of proliferation rate}

To examine the proliferation activity of IL-33 positive and ST2 positive cells, ESCC and control sections were stained with IL-33/Ki67 (1:70; BD Pharmingen., San Jose, CA, USA) and ST2/Ki67 antibodies according to the protocol described in our previous publication [55-57]. After ESCC sections incubated with primary antibodies at $4{ }^{\circ} \mathrm{C}$ overnight, IL-33-immunoreactivity (IR) was developed with Texas red-, ST2-IR with Cy3- and Ki67-IR with FITCconjugated secondary antibodies (all from Jackson ImmunoRearch Lab., West Grove, PA, USA). Mounted in glycerol, and viewed with confocal microscopy (LSM-700, Carl Zeiss, Jena, Germany) respectively. Colorectal adenoma/cancer sections known positive for IL-33/Ki67 and ST2/Ki67 IRs were used as positive controls. Sections with isotypematched antibodies were used as negative controls in each DIF test and observed and photographed with a confocal microscopy (LSM-700, Carl Zeiss, Jena, Germany).

\section{DIF for the examination of the co-expression of IL-33 with its functional receptor ST2}

To observe the co-expression of IL-33 with its functional receptor, ST2, in both ESCC and stromal cells, we therefore performed DIFs with IL-33/ST2 antibodies according to the protocol as described above; IL-33-IR was developed with Texas red- and ST2-IR with FITC-conjugated secondary antibodies. Isotype-matched negative controls were routinely performed.

\section{Morphometric evaluation of IHC and DIF}

All the stained slides were evaluated under light microscopy and positive cells for IL-33 and ST2 in both ESCC mass and stroma were semi-quantitatively graded respectively. The numbers of cells positive for IL-33- or ST2-IRs in three wellorientated high-power fields $(400 \times)$ with abundant distribution were graded as follows: (score 0 ), $<30 \%$ of total cell mass; (score 1), 30\%-50\% of total cell mass; (score 2), $50 \%-$ $70 \%$ of total cell mass; (score 3 ), $>70 \%$ of total cell mass. The densities of Ki67/IL-33 and Ki67/ST2 double positive cells in both the epithelium and stroma in DIFs were quantified under three well-orientated middle-power fields $(200 \times)$ in 10 ESCC and control sections respectively. The average values of positive cells per slide were used for statistical analysis.

\section{Statistical analysis}

Data were present as median values plus $95 \%$ confidence interval (CI) unless otherwise stated. $P$ values were evaluated by the Mann-Whitney test. The correlation between the IL-33/ST2 axis expression and clinical pathological variables was analyzed. Kaplan-Meier analysis was used to determine survival rates and differences in survival curves, the Cox proportional hazards regression model with a stepwise procedure was used to analyze the simultaneous influence of prognostic factors in available ESCC patients. $P$ value $<0.05$ was considered statistically significant.

\section{Results}

Expression of IL-33 and its functional receptor ST2 in ESCC cells and stromal cells

We first examined expression of IL-33 and its functional receptor ST2 in ESCC cells and stromal cells by immunohistochemistry. As has been shown in our repost from human colorectal cancer [35], IL-33-IR was predominantly detected in nuclear of squamous epithelial cells and stromal cells in both ESCC and control tissues. In control tissues, IL-33-IR were mostly observed in the surface cells of normal epithelium (arrow pointed in Fig. 1A) and stromal cells (arrowhead pointed in Fig. 1A). The expression of IL-33-IR in ESCC cells was slightly increased (arrow pointed in Fig. 1B), but it was significantly increased in the ESCC stroma (arrowhead pointed in Fig. 1B) as compared with the controls.

ST2-IR was detected in both cytoplasm and nuclear of cells. In control tissues, it was observed in the surface cells of normal squamous epithelium (arrow pointed in Fig. 1D) and stromal cells (arrowhead pointed in Fig. 1D). Increased expression of ST2-IR in both ESCC cells (arrow pointed in Fig. 1E) and stromal cells (arrowhead pointed in Fig. 1E) was observed.

When densities of IL-33-IR and ST2-IR positive cells were semi-quantified, data confirmed above IHC observations, and showed increased density scores of IL-33-IR positive cells in the ESCC stroma and increased density scores of ST2 positive cells in both the ESCC and tumor stroma compared to the control tissue (see Table 2).

\section{The correlation between IL-33/ST2 expression and various clinicopathological parameters and prognosis in patients with ESCC}

Subsequently, the correlation between density scores of IL-33/ST2 positive cells and clinicopathological variables such as TNM pathological classification, invasion depth and node involvement were investigated. Results showed that density scores of IL-33-IR positive and ST2-IR positive cells in both the ESCC mass and 


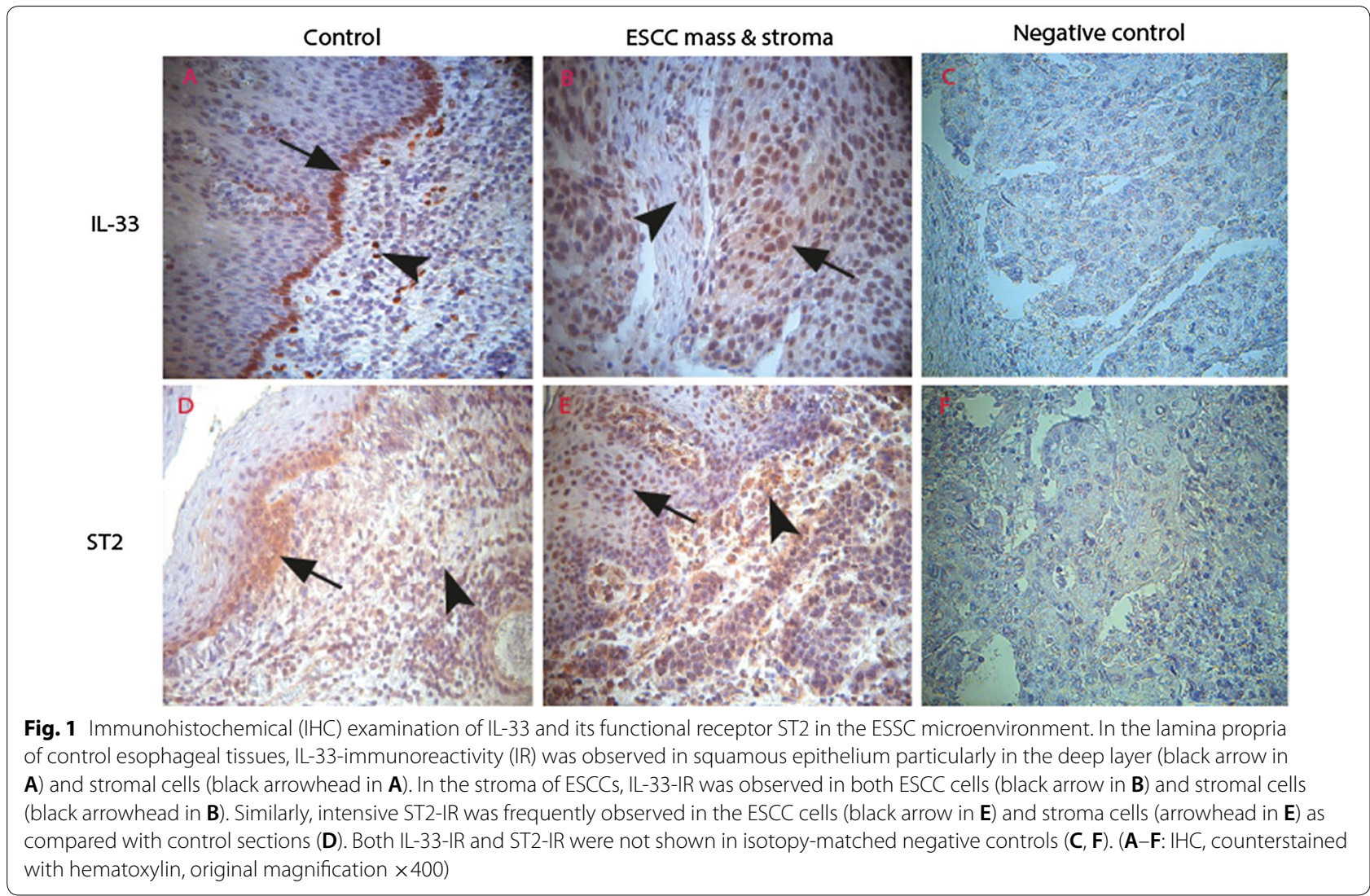

Table 2 Density scores of IL-33-IR and ST2-IR positive cells in the ESCC specimens

\begin{tabular}{lllll}
\hline & Location & Control & ESCC & $P$ \\
\hline IL-33 & Epithelium & $2.0(1.07-2.47)$ & $2.0(1.56-2.34)$ & $>0.05$ \\
& Stroma & $1.0(0.59-2.02)$ & $2.0(1.8-2.40)$ & $<0.05$ \\
St2 & Epithelium & $1.0(0.15-2.13)$ & $3.0(2.00-2.60)$ & $<0.05$ \\
& Stroma & $1.0(0.18-2.07)$ & $3.0(2.27-2.68)$ & $<0.01$ \\
\hline
\end{tabular}

$P$ values are derived from Mann-Whitney tests

stroma correlated with TNM stages (Table 3). Patients with earlier stages (stage I or II) had lower density scores of either IL-33-IR positive or ST2-IR positive cells than those with advanced stages (see Table 3, all $\mathrm{P}$ values were from Mann-Whitney tests). Density scores of IL-33-IR positive cells in the ESCC stroma and ST2-IR positive cells in both the ESCC mass and stroma correlated with positive node involvement (see Table 3). In addition, density scores of ST2-IR positive stromal cells in the ESCC showed a positive correlation with tumor invasion depth, ESCC patients with all layer invasion had a higher density score of ST2-IR positive stromal cells than those with only muscular invasion (see Table 3).
Finally, Kaplan-Meier survival curves revealed that density scores of neither IL-33-IR positive (Fig. 2a, b) nor ST2-IR positive cells (Fig. 2c, d) in both the ESCC mass and stroma correlated with the overall survival in patients with ESCC.

\section{Proliferation activity of IL-33 positive and ST2 positive cells in the ESCC}

The analysis demonstrated that both IL-33-IR positive (Fig. 3A-F) or ST2-IR positive (Fig. 3G-L) ESCC tumor cells and stromal cells had a high proliferative rate. Quantitative data showed that densities of Ki67/ IL-33 and Ki67/ST2 positive cells were increased in both ESCC and stromal cells as compared with controls (Ki67/IL-33 in ESCC vs. control: 17.0 (13.98-20.22) vs. 11.50 (10.28-14.92), $\mathrm{P}<0.05$; Ki67/IL-33 in stroma vs. control: $23.00(18.09-26.51)$ vs. 17.50 (13.4220.38), $\mathrm{P}<0.05$. Ki67/ST2 in ESCC vs. control: 14.50 (10.48-17.72) vs. $9.02(6.06-12.14), \mathrm{P}<0.05 ; \mathrm{Ki67/}$ ST2 in stroma vs. control: $18.0(15.31-21.49)$ vs. 10.0 (7.64-13.56), $\mathrm{P}<0.01$. $\mathrm{P}$ values were obtained from the Mann-Whitney test). 
Table 3 Correlation between density scores of IL-33-IR/ ST2-IR positive cells and TNM stage, node involvement and invasion depth in patients with ESCC

\begin{tabular}{|c|c|c|c|c|}
\hline \multirow[t]{2}{*}{ Parameters } & \multicolumn{2}{|c|}{$\begin{array}{l}\text { IL-33-IR positive cell } \\
\text { density scores }\end{array}$} & \multicolumn{2}{|c|}{$\begin{array}{l}\text { ST2-IR positive cell density } \\
\text { scores }\end{array}$} \\
\hline & ESCC & Stroma & ESCC & Stroma \\
\hline \multicolumn{5}{|l|}{ TNM stage } \\
\hline$I+\|$ & $\begin{array}{l}2.0(0.87- \\
2.53)\end{array}$ & $\begin{array}{l}1.5(0.90- \\
1.90)\end{array}$ & $\begin{array}{l}2.0(1.27- \\
2.53)\end{array}$ & $2.0(1.52-2.48)$ \\
\hline III & $\begin{array}{l}3.0(2.30- \\
2.77)\end{array}$ & $\begin{array}{l}3.0(2.14- \\
2.72)\end{array}$ & $\begin{array}{l}3.0(2.08- \\
2.78)\end{array}$ & $3.0(2.41-2.82)$ \\
\hline$P$ value & $<0.05$ & $<0.01$ & $<0.05$ & $<0.05$ \\
\hline \multicolumn{5}{|c|}{ Node involvement } \\
\hline Positive & $\begin{array}{l}2.5(1.93- \\
3.08)\end{array}$ & $\begin{array}{l}3.0(2.41- \\
3.26)\end{array}$ & $\begin{array}{l}3.0(2.13- \\
3.21)\end{array}$ & $2.0(1.93-3.08)$ \\
\hline Negative & $\begin{array}{l}3.0(2.02- \\
2.61)\end{array}$ & $\begin{array}{l}2.0(1.73- \\
2.32)\end{array}$ & $\begin{array}{l}3.0(1.89- \\
2.58)\end{array}$ & $2.0(2.24-2.70)$ \\
\hline Pvalue & $>0.05$ & $<0.05$ & $<0.05$ & $<0.05$ \\
\hline \multicolumn{5}{|c|}{ Invasion depth } \\
\hline Muscular & $\begin{array}{l}3.0(1.49- \\
3.26)\end{array}$ & $\begin{array}{l}1.5(1.00- \\
2.25)\end{array}$ & $\begin{array}{l}2.5(1.51- \\
2.99)\end{array}$ & $2.0(1.55-2.45)$ \\
\hline All layer & $\begin{array}{l}2.0(1.39- \\
2.29)\end{array}$ & $\begin{array}{l}2.5(1.88- \\
2.56)\end{array}$ & $\begin{array}{l}3.0(1.99- \\
2.69)\end{array}$ & $3.0(2.37-2.82)$ \\
\hline$P$ value & $>0.05$ & $>0.05$ & $>0.05$ & $<0.05$ \\
\hline
\end{tabular}

$P$ values were derived from Mann-Whitney tests
IL-33 and its functional receptor ST2 are expressed in same cells in the ESCC

DIF results indicated that some of ESCC cells (Fig. 4AC) and stromal cells (Fig. 4D-F) were positive for both IL-33-IR and ST2-IR, implying that these cells could either be the cellular sources or target for IL-33 and ST2 in the ESCC.

\section{Discussion}

In this study, we investigated cellular features of IL-33 and its functional receptor, ST2, expressions and evaluated its clinicopathological significance in patients with ESCC. We found that expressions of IL-33 and ST2 were significantly increased in both ESCC cells and stromal cells with a high proliferation rate. Density scores of either IL-33-IR or ST2-IR positive cells in the ESCC stroma correlated with advanced clinicopathological variables i.e. TNM stage, node involvement and invasion depth, which may suggest that the IL-33/ST2 axis is involved in the progression of human ESCC. To best of our literature knowledge, the current study is the first study to characterize the cellular and clinicopathological features of the IL-33/ST2 axis in patients with ESCCs.

Although there has been considerable interest in the essential role of IL-33/ST2 axis in tumorigenesis [18, 30,

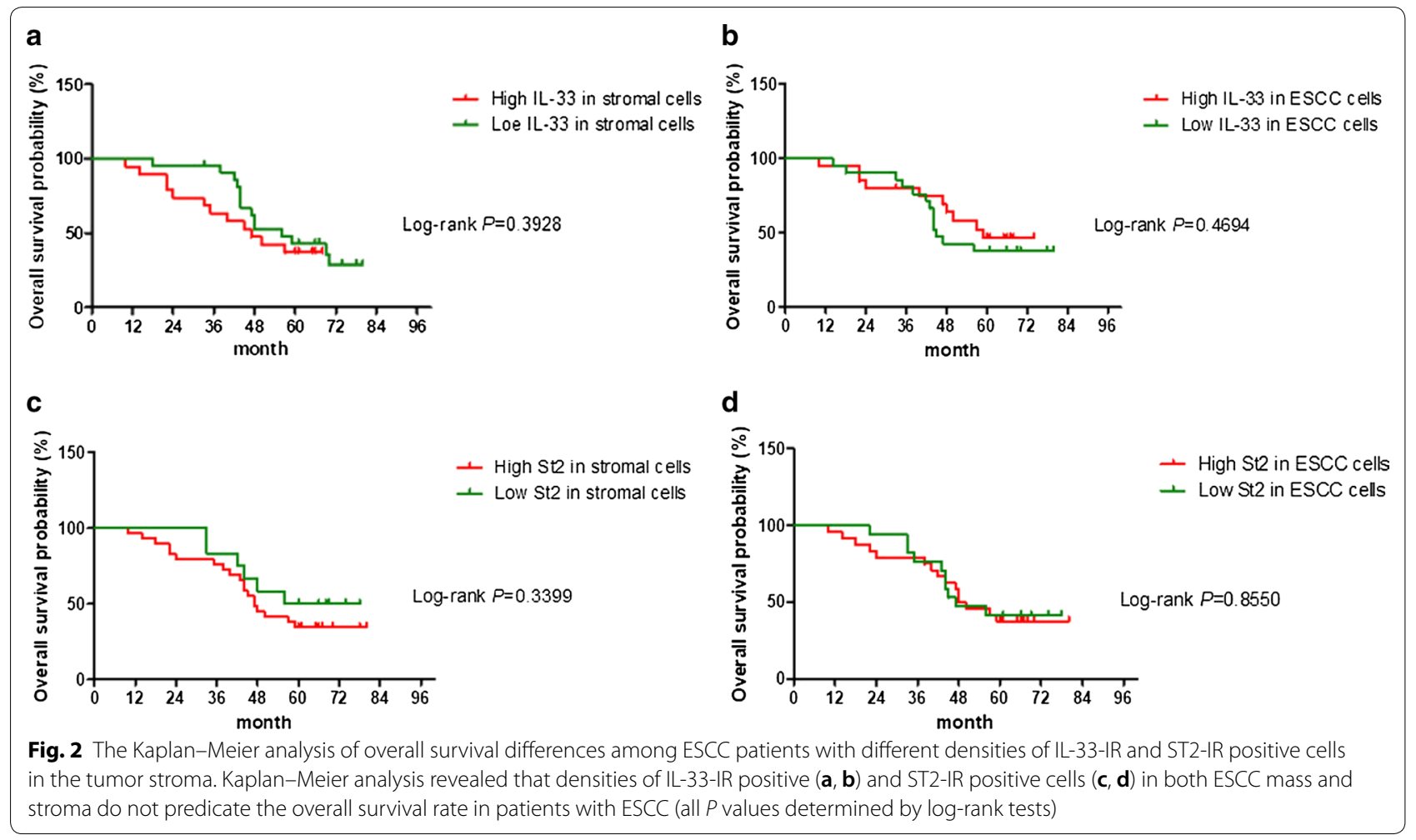




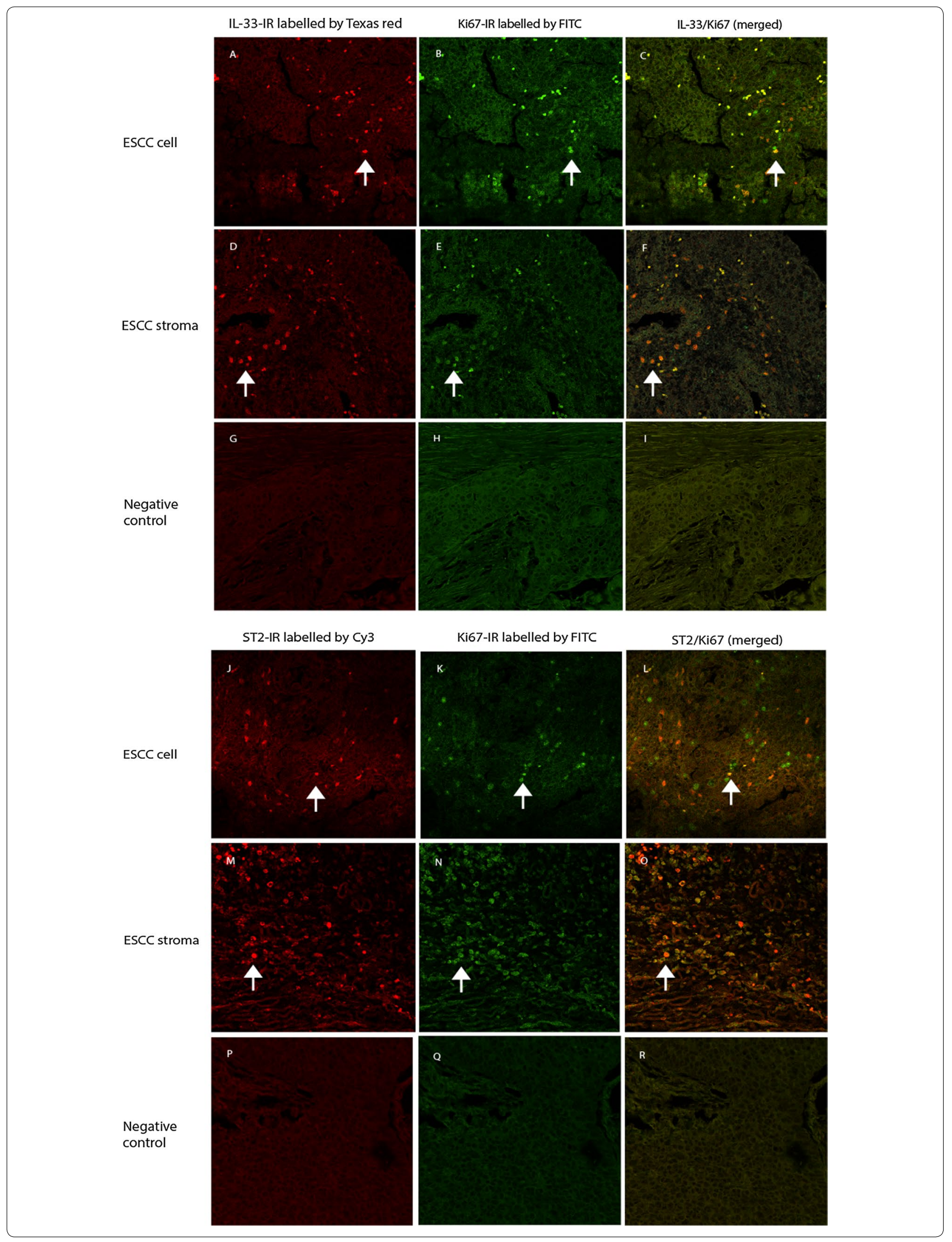




\section{(See figure on previous page.)}

Fig. 3 Double immunofluorescence (DIF) staining with confocal microscopy to evaluate proliferative activity of IL-33-IR and ST2-IR positive cells in the ESCC mass and stroma. DIFs images revealed that IL-33-IR (labelled by Texas red, red cells) in the ESCC mass (A) and stroma (D) was frequently co-localized (merged images in C, F) with a high rate of Ki67-IR (labelled by FITC, green cells in B, E). ST2-IR (labelled by Cy3, red cells) in the ESCC mass $(\mathbf{J})$ and stroma (M) was co-localized (merged images in $\mathbf{L}, \mathbf{O}$ ) with a high rate of Ki67-IR (labelled by FITC, green cells in $\mathbf{K}, \mathbf{N}$ ). IRs for targeted proteins were not shown in both isotopy-matched negative controls for each DIF (see $\mathbf{G}-\mathbf{I}$, and $\mathbf{P}-\mathbf{R}$ respectively). (A-R: DIFs, original magnification $\times 200$; counterstaining was not applied)

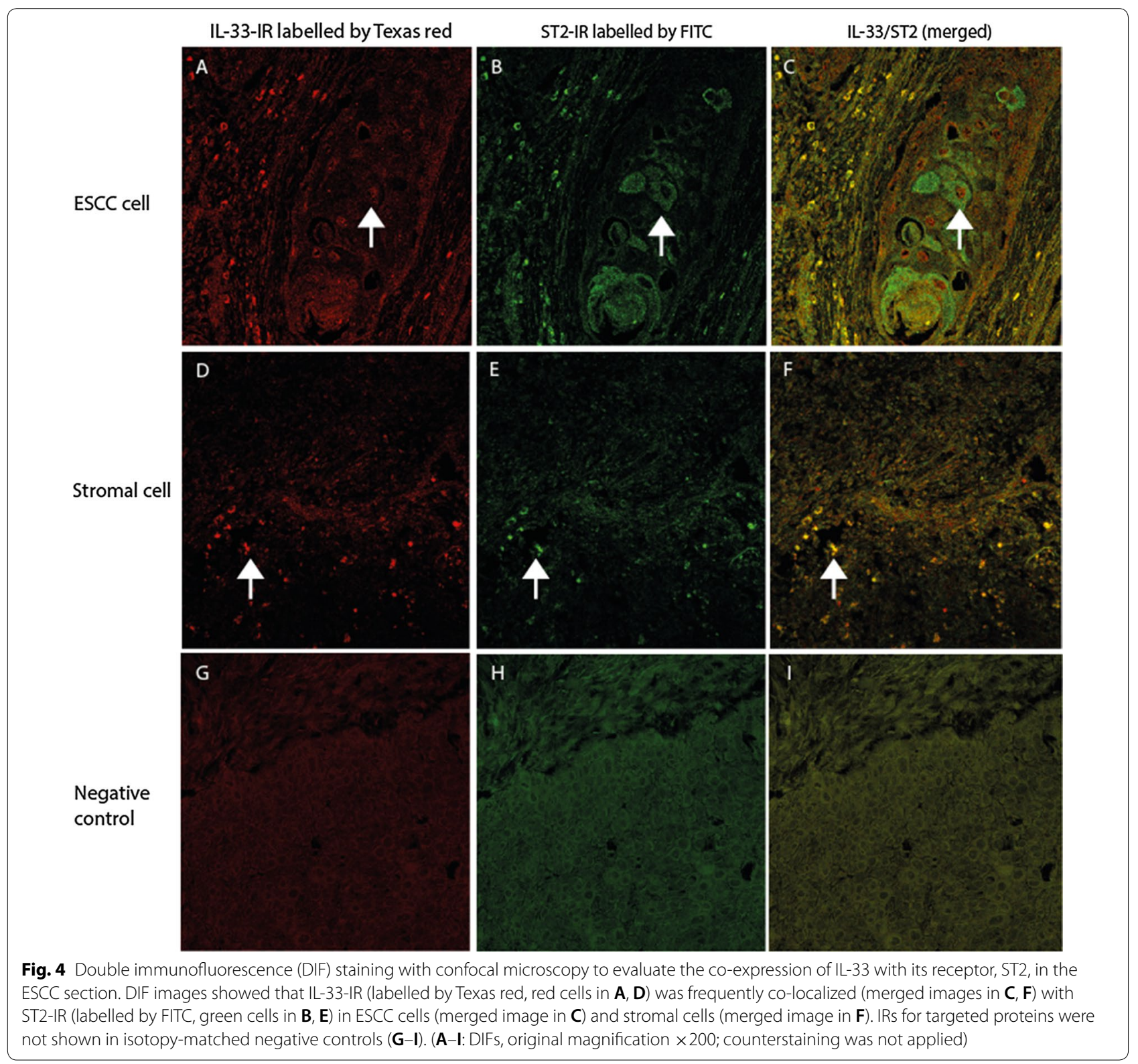

31], studies have provided contradictory results with both pro-tumor and anti-tumor effect reported [29-31, 58]. It appears likely that such different roles might be related to the types of tumor studied and the models used [29-31, 58]. Thus, the role of IL-33/ST2 axis in human tumors has been the subject of controversy, because of its complexity and context dependence. In this study, we were able to demonstrate that both IL-33-IR and its functional receptor ST2-IR were highly expressed in ESCC cells and stromal cells, where most of the cells were actively 
proliferating. Taken together with previous finding that IL-33 is an early alarm signal rapidly released from producing cells upon cellular damage or cellular stress [59], our findings may suggest that such increased expression of the IL-33/ST2 axis in the ESCC might be reflect the an active IL-33/ST2 immune reaction during esophageal tumorigenesis.

It has been recently reported that the expression of IL-33 is associated with clinicopathological variables in certain types of cancers $[25,34,46]$. We therefore analyzed the clinicopathological significance of IL-33 and ST2 expressions in different compartment elements in the ESCC. Results did show that density scores of IL-33-IR positive or ST2-IR positive cells in the ESCC stroma were closely associated advanced clinicopathological variables i.e. TNM stages and invasion depth, these data suggest that the IL-33/ST2 axis is involved in the progression of human ESCC. However, KaplanMeier survival curve analysis showed that density scores of neither IL-33-IR positive nor ST2-IR positive cells in different compartments were associated with overall survival in patients with ESCC. This may reflect the fact that a complex network with multiple elements such as growth factors, immune function, angiogenesis and stroma response, rather than a sole cytokine determines the prognosis of human tumors [9].

Regarding the mechanisms of IL-33/ST2 axis promoting tumorigenesis, increasing evidence suggests that one of the possibilities is through the activation of tumor stroma [30, 60, 61]. Our double immunofluorescence images showed that both IL-33-IR and ST2-IR positive ESCC cells and stromal cells showed a high proliferative rate, which indicates an active IL-33/ST2 response occurred in the ESCC microenvironment. Furthermore, we found that IL-33- and its receptor ST2 IRs were observed in both ESCC cells and stromal cells, which confirmed that these cells could be either the cellular sources or target for IL-33. Whether there is an autocrine or paracrine action way need to be explore in vitro, which might help to design novel translationaltargeted agents in the future.

\section{Conclusion}

Data present in this study add an advance in our understanding of the role of IL-33/ST2 axis in ESCC progression, by demonstrating high expression levels of IL-33 and its primary functional receptor ST2 in ESCC and stromal cells, which are associated with advanced clinicopathological variables. This new work also supports exploration of designing novel translational-targeted agents. Together with other recent researches of the IL-33/ST2 axis in human cancers [35], our work supports the hypothesis that the IL-33/ST2 axis may play an important role in ESCC progression. Although more studies are required involving additional work to explore the exact mechanisms of the IL-33/ST2 axis in ESCC progression, the weight of evidence supports a contributing role for IL-33 and its receptor ST2 to the stromal activation of ESCC, which may result in the development of new therapeutic targets for ESCC treatment.

\section{Abbreviations}

ESCC: esophageal squamous cell carcinoma; IL: interleukin; IHC: immunohistochemistry; DIF: double immunofluorescence; FITC: fluorescein; Cl: confidence interval; TNM: tumor/node/metastasis.

\section{Authors' contributions}

CG designed the project, analyzed data, YA did the immunohistochemistry and double immunofluorescence staining. RJ did histological diagnosis and reviewed the immunohistochemical staining slides; XG, LZ and ZW collected clinical samples and joined the discussion. All authors read and approved the final manuscript.

\section{Author details}

${ }_{1}^{1}$ Research Group of Gastrointestinal Diseases, the Second Affiliated Hospital of Zhengzhou University, Zhengzhou, Henan, China. ${ }^{2}$ Faculty of Health Science, Nord University, Campus Levanger, Levanger, Norway. ${ }^{3}$ Department of Pathology, the Second Affiliated Hospital of Zhengzhou University, Zhengzhou, Henan, China. ${ }^{4}$ Faculty of Chemistry, Biotechnology and Food Science, Norwegian University of Life Sciences, Ås, Norway.

\section{Acknowledgements}

Not applicable.

\section{Competing interests}

The authors declare that they have no competing interests.

\section{Availability of data and materials}

Data to support this study were based on analysis of immunohistochemistry and histological diagnosis from patients with ESCC admitted to our hospital.

\section{Consent for publication}

Not applicable.

\section{Ethics approval and consent to participate}

The study was approved by the local Medical Research Committee of the Second Affiliated Hospital, Zhengzhou University and written informed consents were obtained from patients.

\section{Funding}

This research was supported by the program of Innovation Scientists and Technicians Troop Construction Projects of Henan Province, China (Program No. CXTD20150009, to Cui G) and the grant from Olav Raagholt og Gerd Meidel Raagholts stiftelse for forskning, Norway (No. 2017, to Cui G).

\section{Publisher's Note}

Springer Nature remains neutral with regard to jurisdictional claims in published maps and institutional affiliations.

Received: 9 July 2018 Accepted: 6 December 2018

Published online: 11 December 2018 


\section{References}

1. Zhang HZ, Jin GF, Shen HB. Epidemiologic differences in esophageal cancer between Asian and Western populations. Chin J Cancer. 2012;31(6):281-6

2. Ke L. Mortality and incidence trends from esophagus cancer in selected geographic areas of China circa 1970-1990. Int J Cancer J Int Du Cancer 2002:102(3):271-4.

3. Papaxoinis G, Weaver JMJ, Khoja L, Patrao A, Stamatopoulou S, Alchawaf A, Owen-Holt V, Germetaki T, Kordatou Z, Mansoor W. Significance of baseline FDG-PET/CT scan as a method of staging regional lymph nodes in patients with operable distal oesophageal or gastroesophageal junction adenocarcinoma. Acta Oncol. 2017:56(9):1224-32.

4. Wu Y, Chen X, Liang Y, Li J, Zhang K, Dai L, Guan X, Wang K, Bai Y. Overexpression of long non-coding RNA SOX2OT promotes esophageal squamous cell carcinoma growth. Cancer Cell Int. 2018;18:76.

5. Li F, LV JH, Liang L, Wang JC, Li CR, Sun L, Li T. Downregulation of microRNA-21 inhibited radiation-resistance of esophageal squamous cell carcinoma. Cancer Cell Int. 2018:18:39.

6. Liu B, Pan CF, Yao GL, Wei K, Xia Y, Chen YJ. The long non-coding RNA AK001796 contributes to tumor growth via regulating expression of p53 in esophageal squamous cell carcinoma. Cancer Cell Int. 2018;18:38.

7. Singh S, Saraya A, Das P, Sharma R. Increased expression of MARCH8, an E3 ubiquitin ligase, is associated with growth of esophageal tumor. Cancer Cell Int. 2017;17:116

8. O'Sullivan KE, Phelan JJ, O'Hanlon C, Lysaght J, O'Sullivan JN, Reynolds JV. The role of inflammation in cancer of the esophagus. Exp Rev Gastroenterol Hepatol. 2014;8(7):749-60.

9. Shi Y, Li Z, Zheng W, Liu X, Sun C, Laugsand JB, Liu Z, Cui G. Changes of immunocytic phenotypes and functions from human colorectal adenomatous stage to cancerous stage: update. Immunobiology. 2015:220(10):1186-96.

10. Diakowska D. Cytokines association with clinical and pathological changes in esophageal squamous cell carcinoma. Dis Markers. 2013;35(6):883-93.

11. Nabeki B, Ishigami S, Uchikado Y, Sasaki K, Kita Y, Okumura H, Arigami T, Kijima Y, Kurahara H, Maemura K, et al. Interleukin-32 expression and Treg infiltration in esophageal squamous cell carcinoma. Anticancer Res. 2015:35(5):2941-7.

12. Schmitz J, Owyang A, Oldham E, Song Y, Murphy E, McClanahan TK, Zurawski G, Moshrefi M, Qin J, Li X, et al. IL-33, an interleukin-1-like cytokine that signals via the $\mathrm{IL}-1$ receptor-related protein ST2 and induces Thelper type 2-associated cytokines. Immunity. 2005;23(5):479-90.

13. Seidelin $J B$, Rogler $G$, Nielsen $\mathrm{OH}$. A role for interleukin-33 in $\mathrm{T}(\mathrm{H}) 2$-polarized intestinal inflammation? Mucosal Immunol. 2011:4(5):496-502.

14. Ramadan A, Land WG, Paczesny S. Editorial: danger signals triggering immune response and inflammation. Front Immunol. 2017:8:979.

15. Peine M, Marek RM, Lohning M. IL-33 in T cell differentiation, function, and immune homeostasis. Trends Immunol. 2016;37(5):321-33.

16. He Z, Chen L, Souto FO, Canasto-Chibuque C, Bongers G, Deshpande M, Harpaz N, Ko HM, Kelley K, Furtado GC, et al. Epithelial-derived IL-33 promotes intestinal tumorigenesis in Apc Min/+ mice. Sci Rep. 2017;7(1):5520.

17. Nabekura T, Girard JP, Lanier LL. IL-33 receptor ST2 amplifies the expansion of NK cells and enhances host defense during mouse cytomegalovirus infection. J Immunol. 2015;194(12):5948-52.

18. Wasmer MH, Krebs P. The Role of IL-33-dependent Inflammation in the tumor microenvironment. Front Immunol. 2016;7:682.

19. De la Fuente M, MacDonald TT, Hermoso MA. The IL-33/ST2 axis: role in health and disease. Cytokine Growth Factor Rev. 2015;26(6):615-23.

20. Griesenauer B, Paczesny S. The ST2/IL-33 axis in immune cells during inflammatory diseases. Front Immunol. 2017;8:475

21. Jovanovic IP, Pejnovic NN, Radosavljevic GD, Pantic JM, Milovanovic MZ, Arsenijevic NN, Lukic ML. Interleukin-33/ST2 axis promotes breast cancer growth and metastases by facilitating intratumoral accumulation of immunosuppressive and innate lymphoid cells. Int J Cancer J Int Du Cancer. 2014;134(7):1669-82.

22. Kim JY, Lim SC, Kim G, Yun HJ, Ahn SG, Choi HS. Interleukin-33/ST2 axis promotes epithelial cell transformation and breast tumorigenesis via upregulation of COT activity. Oncogene. 2015;34(38):4928-38.

23. Xiao P, Wan X, Cui B, Liu Y, Qiu C, Rong J, Zheng M, Song Y, Chen L, He $J$, et al. Interleukin 33 in tumor microenvironment is crucial for the accumulation and function of myeloid-derived suppressor cells. Oncoimmunology. 2016;5(1):e1063772.

24. Schmieder A, Multhoff G, Radons J. Interleukin-33 acts as a pro-inflammatory cytokine and modulates its receptor gene expression in highly metastatic human pancreatic carcinoma cells. Cytokine. 2012;60(2):514-21.

25. Chen SF, Nieh S, Jao SW, Wu MZ, Liu CL, Chang YC, Lin YS. The paracrine effect of cancer-associated fibroblast-induced interleukin-33 regulates the invasiveness of head and neck squamous cell carcinoma. J Pathol. 2013:231(2):180-9.

26. Zhang P, Liu XK, Chu Z, Ye JC, Li KL, Zhuang WL, Yang DJ, Jiang YF. Detection of interleukin-33 in serum and carcinoma tissue from patients with hepatocellular carcinoma and its clinical implications. J Int Med Res. 2012;40(5):1654-61.

27. Tong X, Barbour M, Hou K, Gao C, Cao S, Zheng J, Zhao Y, Mu R, Jiang HR. Interleukin-33 predicts poor prognosis and promotes ovarian cancer cell growth and metastasis through regulating ERK and JNK signaling pathways. Mol Oncol. 2016;10(1):113-25.

28. Saied EM, El-Etreby NM. The role and prognostic value of inducible nitric oxide synthase (iNOS) and interleukin-33 (IL-33) in serous and mucinous epithelial ovarian tumours. Ann Diagn Pathol. 2017:27:62-8.

29. Dominguez D, Ye C, Geng Z, Chen S, Fan J, Qin L, Long A, Wang L, Zhang $Z$, Zhang $Y$, et al. Exogenous IL-33 restores dendritic cell activation and maturation in established cancer. J Immunol. 2017;198(3):1365-75.

30. Lu B, Yang M, Wang Q. Interleukin-33 in tumorigenesis, tumor immune evasion, and cancer immunotherapy. J Mol Med (Berl). 2016;94(5):535-43.

31. Mertz KD, Mager LF, Wasmer MH, Thiesler T, Koelzer VH, Ruzzante G, Joller S, Murdoch JR, Brummendorf T, Genitsch V, et al. The IL-33/ST2 pathway contributes to intestinal tumorigenesis in humans and mice. Oncoimmunology. 2016;5(1):e1062966

32. Wang Z, Xu L, Chang Y, Zhou L, Fu H, Zhang W, Yang Y, Xu J. IL-33 is associated with unfavorable postoperative survival of patients with clear-cell renal cell carcinoma. Tumour Biol. 2016;37(8):11127-34.

33. Hu LA, Fu Y, Zhang DN, Zhang J. Serum IL-33 as a diagnostic and prognostic marker in non- small cell lung cancer. APJCP. 2013;14(4):2563-6.

34. Sun P, Ben Q, Tu S, Dong W, Qi X, Wu Y. Serum interleukin-33 levels in patients with gastric cancer. Dig Dis Sci. 2011;56(12):3596-601.

35. Cui G, Qi H, Gundersen MD, Yang H, Christiansen I, Sorbye SW, Goll $\mathrm{R}$, Florholmen J. Dynamics of the IL-33/ST2 network in the progression of human colorectal adenoma to sporadic colorectal cancer. CII. 2015:64(2):181-90.

36. Milosavljevic MZ, Jovanovic IP, Pejnovic NN, Mitrovic SL, Arsenijevic NN, Simovic Markovic BJ, Lukic ML. Deletion of IL-33R attenuates VEGF expression and enhances necrosis in mammary carcinoma. Oncotarget. 2016;7(14):18106-15.

37. Yamada D, Rizvi S, Razumilava N, Bronk SF, Davila Jl, Champion MD, Borad MJ, Bezerra JA, Chen X, Gores GJ. IL-33 facilitates oncogene-induced cholangiocarcinoma in mice by an interleukin-6-sensitive mechanism. Hepatology. 2015;61(5):1627-42

38. Sponheim J, Pollheimer J, Olsen T, Balogh J, Hammarstrom C, Loos T, Kasprzycka M, Sorensen DR, Nilsen HR, Kuchler AM, et al. Inflammatory bowel disease-associated interleukin-33 is preferentially expressed in ulceration-associated myofibroblasts. Am J Pathol. 2010;177(6):2804-15.

39. Choi YS, Choi HJ, Min JK, Pyun BJ, Maeng YS, Park H, Kim J, Kim YM, Kwon YG. Interleukin-33 induces angiogenesis and vascular permeability through ST2/TRAF6-mediated endothelial nitric oxide production. Blood. 2009;114(14):3117-26.

40. Kuchler AM, Pollheimer J, Balogh J, Sponheim J, Manley L, Sorensen DR, De Angelis PM, Scott H, Haraldsen G. Nuclear interleukin-33 is generally expressed in resting endothelium but rapidly lost upon angiogenic or proinflammatory activation. Am J Pathol. 2008:173(4):1229-42.

41. Jovanovic IP, Pejnovic NN, Radosavljevic GD, Arsenijevic NN, Lukic ML. IL-33/ST2 axis in innate and acquired immunity to tumors. Oncoimmunology. 2012;1(2):229-31

42. Jovanovic I, Radosavljevic G, Mitrovic M, Juranic VL, McKenzie AN Arsenijevic N, Jonjic S, Lukic ML. ST2 deletion enhances innate and acquired immunity to murine mammary carcinoma. Eur J Immunol. 2011;41(7):1902-12.

43. Schiering C, Krausgruber T, Chomka A, Frohlich A, Adelmann K, Wohlfert EA, Pott J, Griseri T, Bollrath J, Hegazy AN, et al. The alarmin IL-33 promotes regulatory T-cell function in the intestine. Nature. 2014;513(7519):564-8. 
44. Curiel TJ, Coukos G, Zou L, Alvarez X, Cheng P, Mottram P, EvdemonHogan M, Conejo-Garcia JR, Zhang L, Burow M, et al. Specific recruitment of regulatory $T$ cells in ovarian carcinoma fosters immune privilege and predicts reduced survival. Nat Med. 2004;10(9):942-9.

45. Yukawa T, Shimizu K, Maeda A, Yasuda K, Saisho S, Okita R, Nakata M. Cyclooxygenase-2 genetic variants influence intratumoral infiltration of Foxp3-positive regulatory T cells in non-small cell lung cancer. Oncol Rep. 2015;33(1):74-80.

46. Bergis D, Kassis V, Ranglack A, Koeberle V, Piiper A, Kronenberger B, Zeuzem S, Waidmann O, Radeke HH. High serum levels of the interleukin-33 receptor soluble ST2 as a negative prognostic factor in hepatocellular carcinoma. Transl Oncol. 2013;6(3):311-8.

47. Marvie P, Lisbonne M, L'Helgoualc'h A, Rauch M, Turlin B, Preisser L, Bourd-Boittin K, Theret N, Gascan H, Piquet-Pellorce C, et al. Interleukin-33 overexpression is associated with liver fibrosis in mice and humans. J Cell Mol Med. 2010;14(6B):1726-39.

48. Wang C, Chen Z, Bu X, Han Y, Shan S, Ren T, Song W. IL-33 signaling fuels outgrowth and metastasis of human lung cancer. Biochem Biophys Res Commun. 2016;479(3):461-8.

49. $Y u X X, H u Z$, Shen $X$, Dong LY, Zhou WZ, Hu WH. IL-33 promotes gastric cancer cell invasion and migration via ST2-ERK1/2 pathway. Dig Dis Sci. 2015;60(5):1265-72.

50. Akimoto M, Hayashi Jl, Nakae S, Saito H, Takenaga K. Interleukin-33 enhances programmed oncosis of ST2L-positive low-metastatic cells in the tumour microenvironment of lung cancer. Cell Death Dis. 2016;7:e2057.

51. Bhardwaj N, Ishmael F, Lehman E, Bethards D, Ruggiero F, Ghaffari G. Effect of topical beclomethasone on inflammatory markers in adults with eosinophilic esophagitis: a pilot study. Allergy Rhinol (Providence). 2017;8(2):85-94.
52. Shan J, Oshima T, Muto T, Yasuda K, Fukui H, Watari J, Nakanishi K, Miwa $H$. Epithelial-derived nuclear IL-33 aggravates inflammation in the pathogenesis of reflux esophagitis. J Gastroenterol. 2015;50(4):414-23.

53. Shan J, Oshima T, Wu L, Fukui H, Watari J, Miwa H. Interferon gammainduced nuclear interleukin-33 Potentiates the release of esophageal epithelial derived cytokines. PLoS ONE. 2016;11(3):e0151701.

54. Sobin L, Gospodarowicz M, Wittekind C. TNM classification of malignant tumours. 7th ed. New York: Wiley; 2009.

55. Cui G, Yuan A, Zhu L, Florholmen J, Goll R. Increased expression of interleukin-21 along colorectal adenoma-carcinoma sequence and its predicating significance in patients with sporadic colorectal cancer. Clin Immunol. 2017;183:266-72

56. Cui G, Yuan A, Sun Z, Zheng W, Pang Z. IL-1 beta/IL-6 network in the tumor microenvironment of human colorectal cancer. Pathol Res Pract. 2018;214(7):986-97.

57. Cui G, Li C, Xu G, Sun Z, Zhu L, Li Z, Zheng W, Li J, Yuan A. Tumor-associated fibroblasts and microvessels contribute to the expression of immunosuppressive factor indoleamine 2,3-dioxygenase in human esophageal cancers. Pathol Oncol Res. 2018;24(2):269-75.

58. Fang M, Li Y, Huang K, Qi S, Zhang J, Zgodzinski W, Majewski M, Wallner G, Gozdz S, Macek P, et al. IL33 promotes colon cancer cell stemness via JNK activation and macrophage recruitment. Can Res. 2017;77(10):2735-45.

59. Cayrol C, Girard JP. IL-33: an alarmin cytokine with crucial roles in innate immunity, inflammation and allergy. Curr Opin Immunol. 2014;31:31-7.

60. Akimoto M, Takenaga K. Role of the IL-33/ST2L axis in colorectal cancer progression. Cell Immunol. 2018. (Epub ahead of print).

61. Maywald RL, Doerner SK, Pastorelli L, De Salvo C, Benton SM, Dawson EP, Lanza DG, Berger NA, Markowitz SD, Lenz HJ, et al. IL-33 activates tumor stroma to promote intestinal polyposis. Proc Natl Acad Sci USA. 2015;112(19):E2487-96.
Ready to submit your research? Choose BMC and benefit from:

- fast, convenient online submission

- thorough peer review by experienced researchers in your field

- rapid publication on acceptance

- support for research data, including large and complex data types

- gold Open Access which fosters wider collaboration and increased citations

- maximum visibility for your research: over 100M website views per year

At BMC, research is always in progress.

Learn more biomedcentral.com/submissions 